Rev. Interd. em Cult. e Soc. (RICS), São Luís, v. 6, n. 1, p. 14- 22, jan./jun. 2020

ISSN eletrônico: 2447-6498

\title{
“A Cela Um”: Uma Leitura do Espaço na Ficção de Chimamanda Ngozi Adichie $^{1}$
}

\section{"Cell One": A Reading of Space in Chimamanda Ngozi Adichie's Ficction}

\author{
CAMILA CANTANHEDE VIEIRA \\ Mestranda do Programa de Pós-Graduação em Letras - UFMA \\ cantamila@gmail.com
}

\section{RESUMO}

Este artigo se propõe a fazer uma análise de "A Cela Um", um dos doze contos que compõem o livro No seu Pescoço, da escritora nigeriana Chimamanda Ngozi Adichie, originalmente lançado em 2009 e traduzido para o português em 2017. Neste conto, a partir da narração de uma jovem, filha de professores universitários moradores do campus, é apresentado ao leitor Nnamabia, seu irmão que, ao longo da vida, quase sempre sai impune das consequências de seus atos, até que é preso por supostamente ser membro de um "culto" e se envolver em um atentado provocado por eles. Para a análise proposta, serão utilizadas as categorias da Geografia Humanista Cultural, mais especificamente de Yi-Fu Tuan, como espaço e lugar, espaciosidade e apinhamento, cujas reflexões encontram-se em sua obra Espaço e Lugar: a perspectiva da experiência (2013), além da busca por um referencial teórico afrocêntrico que aporte a análise proposta.

Palavras-chave: Espaço. Literatura africana. Chimamanda Ngozi Adichie.

\begin{abstract}
This article aims to analyze "Cell One", one of the twelve short stories that make up the book The thing around your neck, by the nigerian writer Chimamanda Ngozi Adichie, originally released in 2009 and translated into portuguese in 2017. In this story, from the narration of a young girl, daughter of university professors, Nnamabia is introduced, the brother who throughout their lives, and that almost always goes unpunished from the consequences of his actions until the day he is arrested for allegedly being a member of a "worship" and engage in an attack provoked by them. For the proposed analysis, we will articulate some categories from the Humanist Cultural Geography, specifically from Yi-Fu Tuan, as space and place, spaciousness and crowding, whose reflections are found in his work Space and Place: the perspective of experience (2013), in addition to the search for an Afrocentric theoretical framework that supports the proposed analysis.
\end{abstract}

Keywords: Space. African literature. Chimamanda Ngozi Adichie.

\section{INTRODUÇÃO}

As artes, em geral, assim como as literaturas produzidas em contextos que, recentemente, saíram da situação de colônia e passaram a usufruir do status de independentes, ganharam um público de leitores bastante interessados em observar como o pós-colonialismo passa a constituir não só um tema recorrente, como também, em alguns países, um estilo adotado por muitos artistas e escritores.

Viabilizando uma nova forma de se olhar para como a história é tecida no cotidiano, a escritora nigeriana Chimamanda Adichie critica a forma como a história de seu país foi forjada por imagens produzidas por narrativas de guerra, de fome e de miséria,

\footnotetext{
${ }^{1}$ Artigo submetido para avaliação em 10/10/2019 e aprovado em 20/10/2019.
} 
Rev. Interd. em Cult. e Soc. (RICS), São Luís, v. 6, n. 1, p. 14- 22, jan./jun. 2020 ISSN eletrônico: $2447-6498$

veiculadas pelos mais diversos materiais produzidos pelas mais diversas áreas do conhecimento, bem como a produção cultural.

Em O perigo da história única, critica fortemente a forma como o conhecimento que se tem da África foi manipulado pelo interesse em manter um sentimento de comiseração por todos os descendentes deste continente. Assim, vender a imagem de um povo que precisava de ajuda era a desculpa para prolongar a relação de dependência.

Enxergar a história apenas da perspectiva das elites mundiais, ainda que sob novas configurações, é um tema que a escritora estende para sua criação literária. Edward Said, crítico e escritor literário, chama a atenção para os blocos que se formaram a partir da Guerra Fria que põem em destaque duas grandes potências mundiais e de como elas manipulam os eventos para repercutirem a seu favor. É o caso, por exemplo, da imagem do Oriente Médio, consequentemente, dos mulçumanos, produzida pela grande mídia mundial. Ganha destaque Chinua Achebe, também nigeriano que, assim como Said, se empenhou em desvelar a perversidade do colonialismo e seus efeitos danosos.

Assim, conceber-se de forma compatível com sua história, cultura e ancestralidade é estar centrada ou centrado. Já o deslocamento ocorre quando alguém apreende a realidade pelo centro de outro grupo. Tendo o povo africano sido deslocado, é importante que qualquer avaliação de suas condições seja feita com base em uma localização centrada em África e suas diásporas.

No Seu Pescoço é o primeiro livro de contos da nigeriana Chimamanda Ngozi Adichie, escrito em 2009 e traduzido para o português em 2017. A escritora dá continuidade a uma corrente de expressões artísticas e intelectuais que visavam à desconstrução de estereótipos redutores criados e repercutidos pelas elites mundiais, que atravessaram as fronteiras de tempo e espaço, se cristalizando como conhecimento legítimo. Essa temática sugere uma análise das relações entre o homem e a sociedade a partir do ponto de vista de quem teve a experiência direta dos efeitos causados por séculos de dependência, para um presente fraturado e um futuro incerto.

$\mathrm{Na}$ intenção de realizar uma leitura interdisciplinar do conto, a convergência da Geografia com a Literatura possibilita o vislumbre de uma nova perspectiva de compreensão do espaço como elemento fundamental das narrativas literárias.

Assim, para a análise a que nos propomos, utilizaremos categorias da Geografia Humanista Cultural, mais especificamente do geógrafo sino-americano Yi-Fu Tuan, como 
Rev. Interd. em Cult. e Soc. (RICS), São Luís, v. 6, n. 1, p. 14- 22, jan./jun. 2020

ISSN eletrônico: 2447-6498

espaço e lugar, espaciosidade e apinhamento, cujas reflexões encontram-se em sua obra Espaço e Lugar: a perspectiva da experiência (2013). Em um entendimento que considera a natureza da realidade geográfica como sendo a própria realidade humana, nos valeremos do conceito de geograficidade de Eric Dardel. Dentre muitas possibilidades de análise, essa teoria se destaca, pois nos leva a perceber como a sensação e a consciência de liberdade se dão gradativamente, enquanto os acontecimentos vão se desenrolando na trama.

\section{2 -A GEOGRAFIA HUMANISTA CULTURAL E A FICÇÃO DE CHIMAMANDA NGOZI ADICHIE}

A noção de "lugar" tem sido objeto de discussão de várias ciências ao longo do tempo. Desde os anos de 1920, uma nova visada epistemológica veio se desenhando quanto à Geografia. A compreensão a respeito do "lugar" não pode mais estar desvinculada do Homem que nele habita, em um entendimento que agora considera a subjetividade relativa à percepção de cada indivíduo e em como isso se reflete na relação do Homem com a Terra.

Esse afastamento da Geografia positivista dá à Geografia uma vertente humanista, permitindo seu entrelaçamento com a Literatura:

O pensamento metafórico ignora os limites bem delimitados da classificação
científica. Como termos científicos, "montanha" e "vale" são tipos de uma categoria
geográfica. No pensamento metafórico, estas palavras carregam simultaneamente,
valores de "alto" e "baixo", os quais, por sua vez, implicam a polaridade de
masculino-feminino e características temperamentais antitéticas (TUAN, 2016, p.
199).

Yi-Fu Tuan (2016), a partir da leitura de Gaston Bachelard, incorporou o termo "topofilia" aos seus estudos geográficos. O entrelaçamento da Geografia com a Literatura possibilitaria a compreensão do espaço sob uma nova perspectiva a partir do texto literário, nos quais é expressa a própria essência geográfica do ser-no-mundo (DARDEL, 2011).

Inocência Mata sustenta que a literatura vai além da sua natureza primária, transcendendo a ficcionalidade, e que não é raro que seja possível, apenas por meio do texto literário, nas diversas perspectivas e propostas textuais, conhecer as "vias do pensamento intelectual nacional” (MATA, 2006, p. 34), que justamente revelam as várias visões sobre o país, o que vai possibilitar a atualização das identidades sociais, no âmbito de sua reconfiguração na contemporaneidade. 
Rev. Interd. em Cult. e Soc. (RICS), São Luís, v. 6, n. 1, p. 14- 22, jan./jun. 2020 ISSN eletrônico: $2447-6498$

Desse modo, é intenção desse artigo investigar como, na literatura africana de língua inglesa, o sujeito se relaciona com seu "espaço geográfico vivido" a partir das categorias espaço e lugar.

Dos doze contos que compõem o livro, o primeiro é "A Cela Um". A partir da narração de uma jovem, filha de professores universitários, moradores do campus, somos apresentados a Nnamabia, seu irmão, um jovem de "pele clara cor de mel” (ADICHIE, 2017, p.12) que, ao longo de sua vida, quase sempre sai impune das consequências de seus atos, até que é preso por supostamente ser membro de um "culto" e se envolver em um atentado provocado por eles.

A referência ao tom da pele do irmão indicia a relação que a narradora faz para explicar a predileção da mãe:

Nnamabia era igualzinho à minha mãe, com a pele clara cor de mel, olhos grandes e uma boca generosa que se curvava perfeitamente. Quando minha mãe nos levava ao mercado, os feirantes gritavam: "Ei! Senhora, por que desperdiçou sua pele clara num menino e deixou a menina tão escura?". E minha mãe ria, como se assumisse uma alegre e travessa responsabilidade pela beleza de Nnamabia (ADICHIE, 2017, p. 12).

Apresenta uma narradora em primeira pessoa, não nomeada, porém identificada como a irmã do personagem sobre o qual o conto se atém, que narra de modo não linear o histórico de pequenos delitos do seu irmão ao longo da vida, a começar pelo roubo da própria casa da família, ocasião em que penhorou as joias de sua mãe por um ínfimo valor:

Nnamabia tinha feito aquilo, eu sabia. Meu pai também sabia. [...] Então, saiu pela porta dos fundos e não voltou para casa naquela noite. [...] Voltou duas semanas mais tarde, magro, cheirando a cerveja, chorando, dizendo que sentia muito e que tinha penhorado as joias com os comerciantes Hausa de Enugu e gastado todo o dinheiro (ADICHIE, 2017, p. 10).

São vários os personagens envolvidos na ação narrativa, contudo a história se concentra em torno de Nnamabia, seus pais e a irmã, além de alguns policiais e detentos. A narrativa de "A Cela Um" é dirigida por essa narradora que, de seu ponto de vista, expõe a predileção de seus pais ao irmão, o que no conto é evidenciado pelo fato de que apenas ele é nomeado. São muitas as situações nas quais é revelada pela atitude da família a predileção pelo irmão, ou o excesso de empatia e compreensão recebida por ele, por exemplo, como nos elenca a irmã-narradora:

Quando, aos onze anos, Nnamabia quebrou a janela da sala de aula com uma pedra, minha mãe deu a ele o dinheiro para pagar pelo conserto e não contou para o meu 
Rev. Interd. em Cult. e Soc. (RICS), São Luís, v. 6, n. 1, p. 14- 22, jan./jun. 2020

ISSN eletrônico: $2447-6498$

pai. Quando ele perdeu alguns livros da biblioteca no segundo ano, ela disse à professora que eles tinham sido roubados pelo menino que trabalhava lá em casa [...] Quando Nnamabia roubou as questões da prova e vendeu para os alunos do meu pai, minha mãe gritou com ele, mas depois disse ao meu pai que Nnamabia afinal de contas já tinha dezesseis anos, e devia receber uma mesada maior (ADICHIE, 2017, p.12-13).

O enredo está focado em Nnamabia e nas circunstâncias que corroboraram sua prisão. À medida que a trama se formata, a partir das rememorações da narradora e das intermitências entre presente e passado, conhecemos com mais detalhes a paradoxal resposta da mãe às contravenções do filho desde a infância.

Para o geógrafo sino-americano Yi-Fu Tuan (2013, p. 14), “as ideias de espaço e lugar não podem ser definidas uma sem a outra. A partir da segurança e estabilidade do lugar, estamos cientes da amplidão, da liberdade e da ameaça do espaço, e vice-versa". Como se pode observar no fragmento abaixo, embora Enugu seja a capital do estado, a percepção da narradora é a de que seja um lugar anônimo, ou seja, um espaço indiferenciado, com o qual não há relação de familiaridade, como demonstra a narradora-personagem:

Nós voltamos para o carro, tomados por um medo inédito. Era possível lidar com aquela situação em Nsukka - nosso campus sossegado e isolado, na nossa cidade ainda mais sossegada e isolada [...] Mas Enugu era um lugar anônimo, a capital do estado [...]. Era o lugar onde a polícia podia fazer o que todos sabiam que fazia quando estava sob pressão para apresentar resultados: matar pessoas (ADICHIE, 2017, p. 16).

Ao se dirigirem para a cidade de Enugu, na intenção de encontrar Nnamabia na prisão, a irmã menciona o "medo inédito" experienciado pela família ao adentrarem aquele espaço, para eles, indiferenciado. A topofobia faz referência ao sentimento de medo ou insegurança relacionado a um determinado espaço ou lugar, sentimentos antitéticos à felicidade e seu par, a topofilia, termo cunhado por Gaston Bachelard e desenvolvido por Tuan (2005), para quem o medo está relacionado tanto aos estados psicológicos como ao meio ambiente real. Para ele, trata-se de "um sentimento complexo, no qual podemos identificar dois componentes: o sinal de alarme e a ansiedade" (TUAN, 2005, p. 12).

A cela é um ambiente sempre citado com a intenção de causar temor ou alguma expectativa de sofrimento iminente. A simples menção à cela faz emergir o sentimento de medo frente a esta situação ameaçadora, que é a de ser levado para aquela cela, especificamente, "a" cela um. Como no fragmento abaixo:

Até o chefe da cela parecia temer a Cela Um. Quando Nnamabia e seus companheiros de cela [...] iam tomar banho no pátio aberto, os policiais que 
Rev. Interd. em Cult. e Soc. (RICS), São Luís, v. 6, n. 1, p. 14- 22, jan./jun. 2020 ISSN eletrônico: $2447-6498$

vigiavam muitas vezes gritavam: "Pare com isso ou você vai para a Cela Um agora!”. Nnamabia tinha pesadelos com a Cela Um (ADICHIE, 2017, p.19).

Já à sensação de falta de espaço causada pela presença de outras pessoas, Tuan (2013) denomina apinhamento, caracterizado pela experiência grupal do espaço, no qual se vive a experiência da outra pessoa (HOLZER, 2003). De outro modo, a sensação de estar livre no espaço, de poder se movimentar nele, Tuan (2013, p. 70) designa de espaciosidade. Assim, para o geógrafo chinês, "espaciosidade está intimamente associada com a sensação de estar livre. Liberdade implica espaço, significa ter poder e espaço suficientes em que atuar”.

A irmã de Nnamabia, durante toda a infância compartilhada com o irmão, experimenta a sensação de apinhamento inspirada por ele, visto que "a companhia de seres humanos - mesmo de uma única pessoa - produz uma diminuição do espaço e ameaça a liberdade" (TUAN, 2013, p. 78). Sua recusa em visitar o irmão na prisão é o empreendimento de uma travessia que visa escapar desse apinhamento:

Na segunda semana, eu disse a meus pais que não iríamos visitar Nnamabia [...] Ouvi os gritos dela. Ouvi a voz do meu pai. Finalmente ficou tudo silencioso e eu não ouvi ninguém ligando o carro. Ninguém foi ver Nnamabia naquele dia. Foi uma surpresa pra mim, aquela pequena vitória (ADICHIE, 2017, p. 21).

De diferente modo, a experiência de viver na cela por alguns dias, inicialmente, traz à Nnamabia a experiência de apinhamento: "Não conseguia imaginar um lugar pior que a sua [cela], tão lotada que muitas vezes ele ficava de pé, pressionado contra a parede rachada". Contudo, o que começa como espaço indiferenciado transforma-se em lugar à medida que o personagem atribui a ele valor e sentido a partir de sua vivência (TUAN, 2013, grifos nossos).

À medida que a trama se desenvolve, a personagem vai se apegando às pessoas e, por fim, à localidade, desenvolvendo por certos lugares, como é o caso da cela, sentimentos que vão dos maus aos bons, dos topofóbicos aos topofílicos, de acordo com as vivências experienciadas. Segundo Tuan (2013, p. 17), a "experiência é um termo que abrange as diferentes maneiras por intermédio das quais uma pessoa conhece e constrói a realidade". É a partir dos sentidos e da experiência no "espaço vivido" que a noção de lugar é construída pelo personagem.

Em uma das visitas da família à prisão, Nnamabia conta a respeito de um acontecimento que, dada a atenção e os detalhes com que narra, parece tê-lo impactado, que foi a chegada de um novo prisioneiro: 
Rev. Interd. em Cult. e Soc. (RICS), São Luís, v. 6, n. 1, p. 14- 22, jan./jun. 2020

ISSN eletrônico: $2447-6498$

Um velho tinha sido empurrado para dentro de sua cela no dia anterior, um homem de mais de setenta anos, com cabelos brancos, a pele fina e enrugada. [...] No dia seguinte, Nnamabia mal tocou no arroz. [...] Ele contou que os policiais tinham jogado água com detergente no chão [...] e que o velho, que não tinha dinheiro para comprar água e não tomava banho há uma semana, tinha corrido para dentro da cela, arrancado a camisa e esfregado as costas magras no chão molhado e cheio de detergente. Os policiais tinham começado a rir (ADICHIE, 2017, p. 23).

A presença desse novo encarcerado à cela poderia ter causado a perda do "espaço em que atuar" (TUAN, 2013, p. 78). Contudo, é a experiência da presença deste "velho" na cela que impulsiona o protagonista a "vencer os perigos" (TUAN, 2013, p. 18), ao reclamar dignidade para os prisioneiros, e é o que lhe dá a consciência e a sensação de liberdade:

Eu gritei com o policial. Disse que o velho era inocente, que estava doente [...] Eles disseram que eu tinha que calar a boca imediatamente ou me levariam para a Cela Um. Não me importei. Não calei a boca. Então eles me pegaram, me bateram e me levaram para a Cela Um (ADICHIE, 2017, p. 27-28).

Segundo Paul Ricoeur (2007), o sentimento é, sem dúvida, intencional: é um sentimento por "alguma coisa" - o amorável, o odioso (por exemplo). "[No sentimento,] uma intenção e uma afeição coincidem em uma mesma experiência” (TUAN, 2013, p. 18). A atitude empática da personagem Nnamabia aponta para essa estranha intencionalidade, posto que o conhecemos pelo olhar parcial de sua irmã, que ora coloca as atitudes do irmão em suspeição, ora tem por ele ternura fraterna.

Com isso, essa relação de afetividade, posteriormente estabelecida na cela, por um lado, indica qualidades sentidas quanto às coisas, quanto às pessoas, quanto ao mundo e, por outro lado, manifesta e revela a maneira pela qual o eu é afetado intimamente. No caso de Nnamabia, a personagem, ao afrontar a ordem vigente, mesmo diante da ameaça de ser levado até à cela, persiste em seu enfrentamento na defesa daquele homem desconhecido. A experiência por meio da vivência de alguns dias na cela em Enugu seria o equivalente à sua redenção.

\section{CONSIDERAÇÕES FINAIS}

A obra de Chimamanda Ngozi Adichie é representativa de um movimento literário que pretende colocar o homem africano na posição de sujeito do conhecimento científico e não como objeto, como demanda a visão eurocêntrica até então recorrente.

Os referenciais literários afrocêntricos enunciam problemáticas políticas, éticomorais, socioculturais, ideológicas e econômicas. Essas temáticas acabam sendo expressas no 
Rev. Interd. em Cult. e Soc. (RICS), São Luís, v. 6, n. 1, p. 14- 22, jan./jun. 2020 ISSN eletrônico: $2447-6498$

texto literário, uma vez que materializam os atos de consciência do autor, que comunica literariamente suas experiências individuais e sua visão de mundo.

A renovação epistemológica da Geografia, de caráter humanista, e sua noção de "lugar" possibilita a compreensão do espaço a partir do texto literário, se voltando para a experiência intuitiva do mundo representado na obra ficcional.

Desse modo, a linguagem literária, dado o seu caráter polissêmico, expressa a realidade humana ao desvelar como o homem se relaciona com o mundo e com os outros, ao mesmo tempo em que revela a condição humana e sua existência por meio de uma linguagem poética, metafórica e simbólica, que "psicografa os anseios e demônios de sua época, dando voz àqueles que se colocam, ou são colocados, à margem da voz oficial: daí poder pensar-se que o indizível de uma época só encontra lugar na literatura” (MATA, 2006, p. 34).

De uma densidade e profundidade temática e estilística intensas, Chimamanda, por meio de sua narrativa, ratifica que os sentimentos topofílico ou seu oposto, a topofobia, evidenciam comportamentos e atitudes que incomodam, apinham, sendo, por vezes, confundidos com uma falsa sensação de liberdade.

\section{REFERÊNCIAS}

ADICHIE, Chimamanda Ngozi. No seu pescoço. $1^{\text {a }}$ ed. São Paulo, SP: Companhia das Letras, 2017.

ACHEBE, Chinua. A educação de uma criança sob o Protetorado Britânico: ensaios. São Paulo, SP: Companhia das Letras, 2012.

BACHELARD, Gaston. A poética do espaço. São Paulo, SP: Martins Fontes, 2008.

CHIZZOTTI, Antonio. Pesquisa qualitativa em ciências humanas e sociais. 6.ed. Petrópolis, RJ: Vozes, 2014.

DARDEL, Eric. O Homem e a Terra: natureza da realidade geográfica. São Paulo, SP: Perspectiva, 2011.

HALBWALCHS, Maurice. A memória coletiva. Trad. Beatriz Sidou. São Paulo: Centauro, 2003.

MATA, Inocência. A crítica literária africana e a teoria pós-colonial: um modismo ou uma exigência?. Juíz de Fora, 2006. 
Rev. Interd. em Cult. e Soc. (RICS), São Luís, v. 6, n. 1, p. 14- 22, jan./jun. 2020 ISSN eletrônico: $2447-6498$

POLLAK, Michael. Memória, esquecimento, silêncio. Estudos Históricos, Rio de Janeiro, vol. 2, n. 3, 1989, p. 3-15.

RICOEUR, Paul. A memória, a história e o esquecimento. Campinas, SP: Editora da Unicamp, 2007.

SAID, Edward. Cultura e Imperialismo. São Paulo: Companhia das Letras, 2011.

TUAN, Yi-Fu. Topofilia: um estudo da percepção, atitudes e valores do meio ambiente. $2^{\mathrm{a}}$ ed. Trad. Lívia de Oliveira. Londrina, PR: EDUEL, 2012.

Espaço e Lugar: a perspectiva da experiência. $2^{\mathrm{a}}$ ed. Trad. Lívia de Oliveira. Londrina, PR: EDUEL, 2013.

Paisagens do medo. Trad. Lívia de Oliveira. São Paulo: Editora da UNESP, 2005. 